\title{
Gait Disorders in Alzheimer's Disease and Other Dementias: There is Something in the Way You Walk
}

\author{
Manuel Montero-Odasso ${ }^{\mathrm{a}, \mathrm{b}, *}$ and George Perry ${ }^{\mathrm{c}}$ \\ ${ }^{a}$ Departments of Medicine (Geriatric Medicine), and Epidemiology and Biostatistics, \\ Schulich School of Medicine \& Dentistry, University of Western Ontario, London, ON, Canada \\ ${ }^{\mathrm{b}}$ Gait and Brain Lab, Parkwood Institute, Lawson Health Research Institute, London, ON, Canada \\ ${ }^{\mathrm{c}}$ Department of Biology and UTSA Neuroscience Institute, University of Texas, San Antonio, Texas, USA
}

Gait impairments are ubiquitous in Alzheimer's disease $(\mathrm{AD})$ and other dementias. Although the main clinical hallmark of dementia is cognitive impairment and decline [1], motor impairments, such as bradykinesia, extrapyramidal rigidity, and gait disorders, have been commonly described, mostly in late stages [1-3]. However, during the last two decades, large epidemiological studies have shown that gait disorders, particularly slowing gait, may be present at early stages of dementia or may even predict who will be at risk of progressing to dementia $[4,5]$.

Specifically, in older adults with mild cognitive impairment (MCI), a pre-dementia state, there is a coexistence of specific cognitive deficiencies and gait abnormalities which provides support to the theory that there is a transition period whereby cognitive loss occurs concurrently with gait slowing [6-8]. These motor impairments are not benign. Older adults with MCI are also at higher risk of falling, with double the incidence of their cognitively healthy counterparts. This higher risk of falls has been related to

\footnotetext{
${ }^{*}$ Correspondence to: Manuel Montero-Odasso, MD, $\mathrm{PhD}$, AGSF, FGSA, FRCPC, 550 Wellington Road E., Rm A3-116, London, ON N6C 0A7, Canada. Tel.: +1 5196854292 /Ext. 42369; Fax: +1 519685 4808; E-mail: mmontero@uwo.ca.
}

poor attention and executive dysfunction affecting the brain's gait control $[9,10]$. Based on these gaitcognitive interactions, it has been postulated that early gait changes can be used as a motor biomarker to detect individuals who are at risk of progression to $\mathrm{AD}$ and non-AD dementias [11-14].

This Journal of Alzheimer's Disease supplemental issue showcases studies presenting the epidemiology of gait disturbances and cognitive impairment, dissecting specific associations between cognitive domains and quantitative gait parameters, and addressing with advanced neuroimaging techniques the potential mechanisms underlying the gait-cognitive interaction seen before dementia. Also, this issue highlights how to manage mobility impairment in the cognitive impaired by using assistive devices.

From an epidemiological perspective, studies from Jayakody et al. [15] and Toots et al. [16] showed that gait speed is associated with further cognitive decline. These confirmatory studies are adding to our current knowledge about the omnipresent interactions between gait and cognition in older adults. Langeard et al. [17] demonstrated that declines in performance on the "Timed Up and Go", a motor per- 
formance test and proxy of gait performance, in older adults can be mediated by dual-task abilities in cognitive switching. Regarding potential mechanisms underlying gait-cognitive interactions in dementia syndromes, functional and structural brain abnormalities, including atrophy of selected cortical and subcortical areas, white matter disease and amyloid- $\beta$ deposition burden, and accentuated depletion of neurotransmitters, are considered key provokers of the concurring cognitive and gait impairments, because control of gait and cognitive performance rely on shared brain networks and regions [18-22]. Adding to this knowledge, Allali et al. [23] showed that structural brain volume covariance is associated with gait speed in patients with MCI, confirming earlier findings [21, 24]. Additionally, Dao et al. [25] showed that cerebral amyloid- $\beta$ deposition is associated with impaired gait speed and lower extremity function.

An emerging approach to address these interactions is using the dual-task gait (DTG) paradigm of walking while performing a concurrent cognitively demanding task as a brain stress test to detect populations at risk. Recently, the DTG test has shown to predict dementia in MCI [13], and this issue includes two studies, Nocera et al. [26] and Cullen et al. [27], that demonstrate the feasibility to perform the DTG test in clinic scenarios. One of these studies also addresses the potential ability of DTG to differentiate cognitive subtyping [27]. Rosso et al. [28] showed the value of DTG to detect individuals at risk of cognitive decline in a cognitive healthy population of older adults. Åhman et al. [29] analyzed associations between DTG performance and AD cerebrospinal fluid biomarkers. This issue presents two studies that showed that motoric cognitive risk syndrome, referring to older individuals that presented both cognitive complaints and slow gait velocity, is associated with frailty [30] and dysfunction of specific quantitative gait parameters [31].

Currently, effective treatments aiming to improve underlying neural mechanisms of high order cognitive functioning are limited to lifestyle interventions, such as physical exercises and cognitive training. These interventions have shown strong signals to improve both cognition and gait in older adults with $\mathrm{MCI}$, mild $\mathrm{AD}$, and other neurodegenerative processes, like Parkinson's disease [32].

Due to the complexity of cognitive-motor interactions, multiple interventions may be necessary to restore or decelerate the decline of cognition and mobility seen in MCI, AD, and related dementias. Finally, pharmacological and non-pharmacological strategies to improve cognition and gait mobility in seniors with $\mathrm{MCI}$ and $\mathrm{AD}$ are becoming increasingly available for various therapeutic approaches, including cholinergic enhancement, cognitive remediation, electrical brain stimulation, dual-task training, and physical exercises. The use of assistive devices in older adults that are cognitively impaired can help to improve their mobility and reduce their falls risk, but also can pose a cognitive challenge. Hunter et al. $[33,34]$ review the effect of learning to use a mobility aid on gait and cognitive demands in AD. Physical activity and mobility can be low in older adults with cognitive impairment, as demonstrated by Taylor et al. [35], who found that older adults with dementia have reduced daily-life activity and impaired dailylife gait when compared to age-sex matched controls.

In sum, this issue of the Journal of Alzheimer's Disease presents the current state of knowledge on the role of gait disturbances and quantitative gait analyses to be used as a motor biomarker to define subtypes of cognitive profiles and to predict cognitive decline and dementias. Similarly, this issue contributes to the understanding of mechanisms underlying the gait and cognition interaction, and reviews the management of cognitive and motor decline using assistive devices and physical activity and exercise training in AD. To end, we congratulate the cadre of authors for their collective fine work presented which certainly moves forward the field of "gait and cognition" in neurodegeneration and aging.

\section{ACKNOWLEDGMENTS}

Dr. Manuel Montero-Odasso's Program in Gait and Brain Health is supported by grants from the CIHR (MOP 211220, PJT 153100), the Ontario Ministry of Research and Innovation (ER11-08-101), the Ontario Neurodegenerative Disease Research Initiative (OBI 34739), the Canadian Consortium on Neurodegeneration in Aging (FRN CNA 137794), and the Department of Medicine Program of Experimental Medicine Research Award at the University of Western Ontario (POEM768915).

\section{REFERENCES}

[1] Waldemar G, Phung KT, Burns A, Georges J, Hansen FR, Iliffe S, Marking C, Rikkert MO, Selmes J, Stoppe G, Sartorius $\mathrm{N}$ (2007) Access to diagnostic evaluation and treatment for dementia in Europe. Int J Geriatr Psychiatry 22, 47-54.

[2] Camicioli R, Howieson D, Oken B, Sexton G, Kaye J (1998) Motor slowing precedes cognitive impairment in the oldest old. Neurology 50, 1496-1498. 
[3] Marquis S, Moore MM, Howieson DB, Sexton G, Payami H, Kaye JA, Camicioli R (2002) Independent predictors of cognitive decline in healthy elderly persons. Arch Neurol 59, 601-606.

[4] Verghese J, Lipton RB, Hall CB, Kuslansky G, Katz MJ, Buschke H (2002) Abnormality of gait as a predictor of non-Alzheimer's dementia. N Engl J Med 347, 1761-1768.

[5] Waite LM, Grayson DA, Piguet O, Creasey H, Bennett HP, Broe GA (2005) Gait slowing as a predictor of incident dementia: 6-year longitudinal data from the Sydney Older Persons Study. J Neurol Sci 229-230, 89-93.

[6] Montero-Odasso M, Bergman H, Phillips NA, Wong $\mathrm{CH}$, Sourial N, Chertkow H (2009) Dual-tasking and gait in people with mild cognitive impairment. The effect of working memory. BMC Geriatr $\mathbf{9}, 41$.

[7] Montero-Odasso M, Verghese J, Beauchet O, Hausdorff JM (2012) Gait and cognition: A complementary approach to understanding brain function and the risk of falling. $J \mathrm{Am}$ Geriatr Soc 60, 2127-2136.

[8] Montero-Odasso M, Hachinski V (2014) Preludes to brain failure: Executive dysfunction and gait disturbances. Neurol Sci 35, 601-604.

[9] Liu-Ambrose TY, Ashe MC, Graf P, Beattie BL, Khan KM (2008) Increased risk of falling in older communitydwelling women with mild cognitive impairment. Phys Ther 88, 1482-1491.

[10] Delbaere K, Kochan NA, Close JC, Menant JC, Sturnieks DL, Brodaty H, Sachdev PS, Lord SR (2012) Mild cognitive impairment as a predictor of falls in community-dwelling older people. Am J Geriatr Psychiatry 20, 845-853.

[11] Montero-Odasso M (2016) Gait as a biomarker of cognitive impairment and dementia syndromes. Quo vadis? Eur J Neurol 3, 437-438.

[12] Montero-Odasso M, Oteng-Amoako A, Speechley M, Gopaul K, Beauchet O, Annweiler C, Muir-Hunter SW (2014) The motor signature of mild cognitive impairment: Results from the gait and brain study. J Gerontol A Biol Sci Med Sci 69, 1415-1421.

[13] Montero-Odasso MM, Sarquis-Adamson Y, Speechley M, Borrie MJ, Hachinski VC, Wells J, Riccio PM, Schapira M, Sejdic E, Camicioli RM, Bartha R, McIlroy WE, MuirHunter S (2017) Association of dual-task gait with incident dementia in mild cognitive impairment: Results from the Gait and Brain Study. JAMA Neurol 74, 857-865.

[14] Verghese J, Annweiler C, Ayers E, Barzilai N, Beauchet O, Bennett DA, Bridenbaugh SA, Buchman AS, Callisaya ML, Camicioli R, Capistrant B, Chatterji S, De Cock AM, Ferrucci L, Giladi N, Guralnik JM, Hausdorff JM, Holtzer R, Kim KW, Kowal P, Kressig RW, Lim JY, Lord S, Meguro K, Montero-Odasso M, Muir-Hunter SW, Noone ML, Rochester L, Srikanth V, Wang C (2014) Motoric cognitive risk syndrome: Multicountry prevalence and dementia risk. Neurology 83, 718-726.

[15] Jayakody O, Breslin M, Srikanth V, Callisaya M (2019) Gait characteristics and cognitive decline: A longitudinal population-based study. J Alzheimers Dis 71, S5-S14.

[16] Toots ATM, Taylor ME, Lord SR, Close JCT (2019) Associations between gait speed and cognitive domains in older people with cognitive impairment. J Alzheimers Dis 71, S15-S21.

[17] Langeard A, Houdeib R, Saillant K, Kaushal N, Lussier M, Bherer L (2019) Switching ability mediates the age-related difference in timed up and go performance. J Alzheimers Dis 71, S23-S28.
[18] Rosano C, Aizenstein HJ, Newman AB, Venkatraman V, Harris T, Ding J, Satterfield S, Yaffe K (2012) Neuroimaging differences between older adults with maintained versus declining cognition over a 10-year period. Neuroimage 62, 307-313.

[19] Rosso AL, Studenski SA, Chen WG, Aizenstein HJ, Alexander NB, Bennett DA, Black SE, Camicioli R, Carlson MC, Ferrucci L, Guralnik JM, Hausdorff JM, Kaye J, Launer LJ, Lipsitz LA, Verghese J, Rosano C (2013) Aging, the central nervous system, and mobility. J Gerontol A Biol Sci Med Sci 68, 1379-1386.

[20] Annweiler C, Montero-Odasso M (2012) Vascular burden as a substrate for higher-level gait disorders in older adults. A review of brain mapping literature. Panminerva Med 54, 189-204.

[21] Annweiler C, Beauchet O, Bartha R, Wells JL, Borrie MJ, Hachinski V, Montero-Odasso M (2013) Motor cortex and gait in mild cognitive impairment: A magnetic resonance spectroscopy and volumetric imaging study. Brain 136, 859871.

[22] Sakurai R, Bartha R, Montero-Odasso M (2018) Entorhinal cortex volume is associated with dual-task gait cost among older adults with MCI: Results From the Gait and Brain Study. J Gerontol A Biol Sci Med Sci, doi: 10.1093/gerona/gly084

[23] Allali G, Montembeault M, Saj A, Wong CH, CooperBrown LA, Bherer L, Beauchet O (2019) Structural brain volume covariance associated with gait speed in patients with amnestic and non-amnestic mild cognitive impairment: A double dissociation. J Alzheimers Dis $\mathbf{7 1}$, S29-S39.

[24] Annweiler C, Beauchet O, Celle S, Roche F, Annweiler T, Allali G, Bartha R, Montero-Odasso M (2012) Contribution of brain imaging to the understanding of gait disorders in Alzheimer's disease: A systematic review. Am J Alzheimers Dis Other Demen 27, 371-380.

[25] Dao E, Hsiung GR, Sossi V, Tam R, Shahinfard E, Nicklin E, Keridy WA, Liu-Ambrose T (2019) Cerebral amyloid- $\beta$ deposition is associated with impaired gait speed and lower extremity function. $J$ Alzheimers Dis $\mathbf{7 1}$, S41-S49.

[26] Nocera JR, Arsik I, Keskinocak P, Lepley-Flood A, Lah JJ, Levey AI, Esper GJ (2019) The feasibility of measuring gait in an outpatient cognitive neurology clinical setting. $J$ Alzheimers Dis 71, S51-S55.

[27] Cullen S, Borrie M, Carroll S, Sarquis-Adamson Y, Pieruccini-Faria F, Montero-Odasso M (2019) Is dual-task gait testing associated with cognitive subtypes in a clinical setting? J Alzheimers Dis 71, S57-S64.

[28] Rosso AL, Metti AL, Faulkner K, Redfern M, Yaffe K, Launer L, Shaaban CE, Nadkarni NK, Rosano C (2019) Complex walking tasks and risk for cognitive decline in high functioning older adults. $J$ Alzheimers Dis 71, S65-S73.

[29] Åhman HB, Giedraitis V, Cedervall Y, Lennhed B, Berglund L, McKee K, Kilander L, Rosendahl E, Ingelsson M, Åberg AC (2019) Dual-task performance and neurodegeneration: Correlations between Timed Up-andGo Dual-Task test outcomes and Alzheimer's disease cerebrospinal fluid biomarkers. J Alzheimers Dis 71, S75-S83.

[30] Sathyan S, Ayers E, Gao T, Milman S, Barzilai N, Rockwood K, Verghese J (2019) Frailty and risk of incident motoric cognitive risk syndrome. J Alzheimers Dis 71, S85-S93. 
[31] Ayers E, Verghese J (2019) Gait dysfunction in motoric cognitive risk syndrome. J Alzheimers Dis 71, S95-S103.

[32] Montero-Odasso M, Speechley M (2018) Falls in cognitively impaired older adults: Implications for risk assessment and prevention. $J$ Am Geriatr Soc 66, 367-375.

[33] Hunter SW, Divine A, Omana H, Wittich W, Hill KD, Johnson AM, Holmes JD (2019) Effect of learning to use a mobility aid on gait and cognitive demands in people with mild to moderate Alzheimer's disease: Part I - Cane. J Alzheimers Dis 71, S105-S114.
[34] Hunter SW, Divine A, Omana H, Wittich W, Hill KD, Johnson AM, Holmes JD (2019) Effect of learning to use a mobility aid on gait and cognitive demands in people with mild to moderate Alzheimer's disease: Part II - 4-Wheeled walker. J Alzheimers Dis 71, S115-S124.

[35] Taylor ME, Brodie MA, van Schooten KS, Delbaere K, Close JCT, Payne N, Webster L, Chow J, McInerney G, Kurrle SE, Lord SR (2019) Older people with dementia have reduced daily-life activity and impaired daily-life gait when compared to age-sex matched controls. J Alzheimers Dis 71, S125-S135. 